\title{
The Effect of Entrepreneurial Leadership on Firm Innovation Through Innovative Work Behavior
}

\author{
Yen Efawati ${ }^{1, *}$ Eeng Ahman $^{2,}$ Disman $^{3,}$ Kusnendi $^{4,}$ Harmon Chaniago ${ }^{5}$ \\ ${ }^{1}$ School of Postgraduate Universitas Pendidikan Indonesia \\ ${ }^{2}$ School of Postgraduate Universitas Pendidikan Indonesia \\ ${ }^{3}$ School of Postgraduate Universitas Pendidikan Indonesia \\ ${ }^{4}$ School of Postgraduate Universitas Pendidikan Indonesia \\ ${ }^{5}$ Politeknik Negeri Bandung \\ *Corresponding author.Email: yenefawati@student.upi.edu
}

\begin{abstract}
This study aims to investigate the relationships between entrepreneurial leadership and innovation and the mediation effects on innovative work behavior. The survey data were based on a sample of 120 employees from 60 Moslem fashion industry sectors in Bandung-Indonesia and analyzed using structural equation modeling. The results of the analysis highlighted that entrepreneurial leadership which was implemented had a significant influence on firm innovation and this effect was mediated by innovative work behavior. The findings of this study suggested that first, entrepreneurial leadership had a significant impact on firm innovation. Second, innovative work behavior mediated the relations between entrepreneurial leadership and firm innovation. This research highlighted the effective role of promoting individual innovation behavior in management practices. Furthermore, commitment to the innovative work behavior of all company members needs to be nurtured, as this is the key to achieve long term sustainability and competitive advantage.
\end{abstract}

Keywords: Entrepreneurial Leadership, Innovative Work Behavior, Firm Innovation.

\section{INTRODUCTION}

Innovation is a key success factor in a firm to achieve long-term sustainability and competitive advantage. However, for business, this is a challenge as well as an opportunity if it is responded by an entrepreneurial action $[1,2]$. Therefore, the necessity of creating or improving products is the main strategy to survive and have competitiveness [3]. According to [4], innovation is a mandatory component of competitiveness that integrates products, new or improved processes, new marketing, and new organizational behavior in business practices. The innovation process through idea creation until implementation that comes from individuals and groups needs to be encouraged from social and psychological aspects so that it becomes an innovative behavior for each member of the company or organization [5]. As a result, many research are developing investigation on the way companies stimulate their employees to contribute to innovation [6-8].
Innovation has been known as the transformation of company-owned knowledge from individuals or groups into products and processes to be introduced to the market [9-11]. Several articles have studied the relationship between innovation and leadership which showed that leadership is a predictor of innovative behavior and innovation [12-14]. Reference [15] argue on their study that the ability of leaders to stimulate the behavior of their employees to innovate can overcome their rivals in a dynamic environment, as well as to create new or improved products, reflected in the new opportunities generated for competitive advantage [16].

Although the scientific literature has analyzed the relationship between leadership and innovation, there is a growing need for an analysis of the relationship between entrepreneurial leadership and firm innovation mediated by individual innovative behavior. To fill this gap, the present study develops a research model that links entrepreneurial leadership, innovative work behavior, and innovation. 
Many have examined the positive impact of the leadership style involved in organizational innovation [17-19]. However, no studies are investigating the mediating effect of innovative behavior on the relationship between entrepreneurial leadership and firm innovation. Furthermore, the creativity of an individual or group that collected be firm innovation comes from the motivation of a leader, so needs to be nurtured continuously to become a culture. Thus, work becomes a pleasant routine and allows for achieving goals.

\subsection{Entrepreneurial leadership (EL) and innovative work behavior (IB)}

Firm innovation is achieved through individual and group creativity [7]. Research conducted by [20] said that in high-tech industries, employee creativity and innovation did not emerge automatically, leaders must support and encourage them into the creative process. They concluded that employees who are involved in creativity and innovation are more suited to be led in a participatory and supportive style, while employees who are not focused on creativity are more suited to leaders who provide specific instructions about the regulations and procedures that must be followed to complete the given task.

Facing high competition and uncertainty, the visionary role is crucial. Using ideas and creativity requires flexibility so that initiatives to create new opportunities continue to develop and produce new resources, technology, and work systems. For this reason, entrepreneurial leadership is needed because it is thought to stimulate people to develop ideas and creativity towards innovation. Entrepreneurial leadership is the ability to influence others by managing resources strategically, emphasizing behavior seeking opportunities and profits [21]. They also stated that entrepreneurs are people who like new ideas and can turn losses into profits.

Employees want to develop ideas and creativity when they realize that innovation will benefit themselves, the organization, and the community. Thus, there is no resistance when the company implements changes in terms of products, processes, and work systems. Innovative behavior will become a culture when there are leaders who motivate intrinsically or extrinsically and facilitate their creative activities [22]. Because individuals ultimately are the ones who produce innovation, it is important to develop and encourage the innovative potential of employees through entrepreneurial leadership that is in line with business activities [23]. Considering the arguments presented, the following hypotheses are constructed:

H1. Entrepreneurial leadership has a positive effect on innovative work behavior.

\subsection{Entrepreneurial leadership (EL) and firm innovation (FI)}

Although some empirical studies show how entrepreneurial leadership influences sustainable growth and value creation [24], empirical evidence showed a positive correlation between these variables [25, 26]. His role is believed to be an innovator because it promotes activities that create or improve company products and processes [27]. Several scientific studies have analyzed the positive relationship between entrepreneurial leadership and innovation [28, 29]. As such, EL will be emphasized as an intangible and invaluable, unique, and difficult to imitate resource that enables organizations to achieve sustainable competitive advantage [30]. A study conducted by [31] involving a sample of 384 SME owners and CEOs in Kuwait empirically showed that EL had a positive influence on a company's innovation ability. Specifically, a company that had a leader with entrepreneurial ability had high potential to design effective and innovative processes, because of its visionary abilities and his ability to communicate shared values, connect ideas, generate new knowledge, and benefit from innovation. Therefore, the following hypotheses are proposed:

H2. Entrepreneurial leadership has a positive effect on firm innovation.

\subsection{The mediating role of innovative work behavior}

Innovative work behavior (IB) often requires constant intrinsic and extrinsic motivation from the company. This is risky if followers perceive change only as modest and tend to maintain the status quo. Innovative behavior aimed at carrying out business strategies will succeed in producing innovation, as emphasized by the literature $[6,32,33]$. Entrepreneurial leadership style can help companies to create useful innovations by involving people as resources with knowledge and ideas. Ability and behavior change into innovative culture can complement each other to face competition and improve innovation performance. Furthermore, innovative behavior often increases selfconfidence [34] and commitment [35], thereby generating more benefits for the company. Innovative work behavior can also increase productivity and business performance which can produce competitive advantages in the company [36].

Furthermore, EL style encourages and empowers innovative behaviors of followers so that entrepreneurial activities produce new products or processes that are more valuable and beneficial to individuals, organizations, and society. The impact of EL on organizations is undeniable, and empirical studies in the scientific literature illustrate the positive effects of these 
variables on IB and firm innovation. Therefore, the following hypothesis is proposed:

H3. Innovative work behavior mediates the relationship between entrepreneurial leadership and firm innovation.

\section{METHODS}

The survey data were collected in a Moslem fashion industry sectors in Bandung-Indonesia employing a quantitative approach and analyzed using structural equation model.

\subsection{Sample}

The study population included SMEs belonging to the Moslem fashion industry sector in BandungIndonesia. This city is a creative economy icon and is a center for Moslem fashion in Indonesia [37]. In general, the fashion industry was the second largest contributor to GDP, namely $18.15 \%$, and the largest creative industry export activities came from the province of West Java at 33.56\% [38]. Companies in the Moslem fashion sector need EL to explore the company's resources and capital to innovate constantly because the fashion world is facing rapid change and keeping pace with the seasons [39].

Data collection from July to December 2019 was conducted to test the hypothesis empirically. Respondents were employees of 60 Moslem fashion industries and the average has been running for at least 5 years. The steps are, first, each HR owner/manager was contacted and asked to choose 2 employees who met one or more criteria, such as have the highest education, perform well, or the best than the others. Second, two questionnaires were sent for each owner/manager to be filled in by employees selected at work. In total, 120 completed questionnaires were received to be analyzed in the study.

\subsection{Measurement}

The questionnaire to measure EL, IB, and FI was developed based on previous literature. The questionnaire was adjusted to the understanding of the employees. All of the measures were rated on a fivepoint Likert type scale, and response options range from 1, "strongly disagree," to 5, "strongly agree".

\subsubsection{Entrepreneurial leadership.}

The ability to influence and direct the performance of group members to achieve organizational goals by recognizing and utilizing entrepreneurial opportunities, developed by [40], using four dimensions: visionary, opportunity seeking, proactivity, and risk-taking propensity with eight-item scale is used to measure it [31].

\subsubsection{Innovation behavior.}

Individual behavior is directed to initiate in the work, group, and organizational roles of new ideas, processes, procedures, and new products [41]. Consists of four dimensions of idea exploration, idea generation, idea championing, and idea implementation were drawing by [42] with a six-item scale developed by [43] used to measure innovation behavior.

\subsubsection{Firm innovation.}

Organizational capacity to improve existing products and/or processes, and the capacity to utilize organizational creativity resources [44]. Using two dimensions namely product innovation and process innovation developed by [45] with a scale of eight items to measure it.

\section{RESULTS AND DISCUSSION}

SPSS 23.0 and Amos software were used to apply statistical analysis.

\subsection{Construct validity and reliability analysis}

The loading factors of all constructs were involved in this study. Experts recommend that a factor loading value $>0.50$ is the minimum level for loading items on a given scale [46]. Based on the result of standardized regression weights, all loading ranges from 0.79 to 0.96 , indicating that the construct validity of the scale is supported. Besides, a reliability analysis was also conducted to check whether the questionnaire items match with the intentions of this study. The Cronbach $\alpha$ value must be at least equal to 0.5 and preferably greater than 0.7 [47]. The reliability analysis results showed that the Cronbach's $\alpha$ values for EL 0.965, IB 0.929, and FI 0.974 , indicating a high level of internal consistency of the scale.

\subsection{Convergent and discriminant validity analysis}

Confirmatory factor analysis was conducted to analyze the convergent and discriminant validity of all constructs by applying the SEM. Two- factor model in which EL, IB, and FI were included. The overall model's $\chi 2$, the comparative fit index/CFI; [48], the Tucker-Lewis index/TLI [49], and the root mean square error of approximation/RMSEA; [50] were used to assess the model fit. Based on Table 1, generally speaking, a value over 0.90 for CFI and TLI and a value below 0.08 for RMSEA indicated a good fit between the proposed model and the observed data [51]. As can be 
observed, all absolute match sizes analyzed are in the appropriate intervals.

Table 1. Results of confirmatory factor analysis for the measures of the variable studied

\begin{tabular}{|l|c|c|l|l|l|}
\hline \multicolumn{1}{|c|}{ Model } & $\boldsymbol{x}^{\mathbf{2}}$ & $\boldsymbol{d} \boldsymbol{f}$ & RMSEA & CFI & TLI \\
\hline 1-factor & 167.345 & 103 & 0.072 & 0.974 & 0.970 \\
3-factor* & 285.291 & 117 & 0.057 & 0.976 & 0.973 \\
\hline
\end{tabular}

Notes: $n=120 .{ }^{*}$ Entrepreneurial leadership and innovative work behavior combined.

Table 1 illustrates the results of the comparison of the different models and shows that the 3 -factor model is better than the 1 -factor model. Referring to the results, the proposed constructs are applied in the next analysis

\subsection{Hypothesis testing}

To analyze the mediating effect of innovative work behavior on the relationship between EL and FI (H3), a competing model analysis was performed [54] using two different models for each firm innovation. The first model examined the same relationship with innovative work behavior acting as mediators (Figure 1). The second model examined the direct relationship between EL and FI (Figure 2). The mediating effect of innovative work behavior on the relationship between EL and FI is said to be supported when:

- the first model explains more of the variance of firm innovation than the second model;

- there is a significant relation between EL and IB, and IB and FI; and

- a significant relationship between EL and FI (as observed in Figure 2) is greatly diminished or eliminated in the first model.

Figure 1 shows each pathway, indicating the hypothesis associated with it as well as estimated path coefficients and the t-values in parentheses ( $t$-values of path coefficients greater than 1.96 are significant at $\mathrm{p}<$ 0.05; t-values of path coefficients greater than 2.58 are significant at $\mathrm{p}<0.01)$ [52]. It can be seen that entrepreneurial leadership has a positive and highly significant effect $(p<0.01)$ on both innovative work behavior and firm innovation. Therefore, $\mathrm{H} 1$ and $\mathrm{H} 2$ are supported.

In Figure 2, it can be seen that the first model provides a better explanation of firm innovation than the second $\left(R^{2}=62 \mathrm{VS} R^{2}=36\right)$. Furthermore, there is a significant relationship between EL, IB, and FI in the full mediation model. Finally, there is a significant relationship between entrepreneurial leadership and innovation for the second model $(\beta=0.6, t=9.09)$, but this relationship decreases in the first model $(\beta=0.17, t$ $=2.38$ ). This means innovative work behavior plays a partial mediatory role in the relation between EL and FI. That means H3 is supported.

This research revealed that innovative work behavior mediates the relationship between EL and FI. There was an attempt to develop a full understanding of the role of leadership and innovative behavior from his follower in creating the innovation of organizations. In response to the research question, first, the empirical results show that leadership and innovative work behavior stimulate the innovation of the Moslem fashion industry. From the theoretical perspective, the results show that this leadership style is effective for increasing organizations' innovation. This finding is in line with previous studies that have shown entrepreneurial leadership and innovative behavior as an effort to create betters innovations, more beneficial to the company [14, 29]. This study also shows that IB mediates the relationship between EL and FI. When organizations possess leaders that facilitating his followers to promote their idea and creativity to be implemented and commercially, they encourage an innovative culture that stimulates the company's innovation performance.

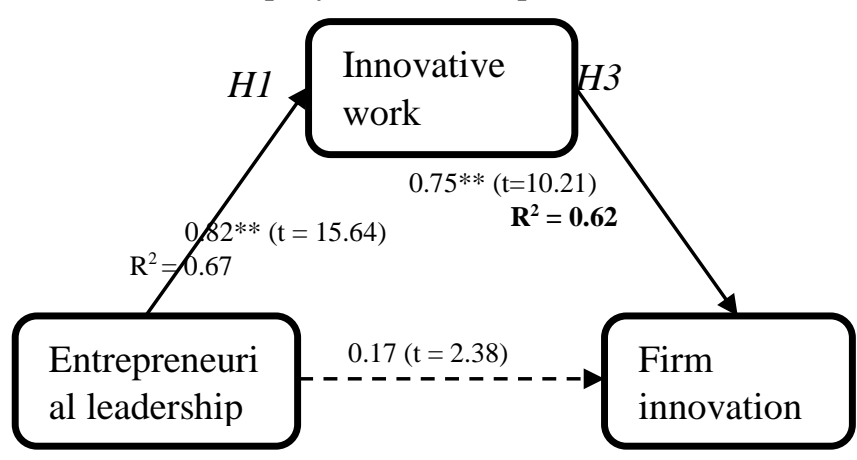

Note: Significant at: $* \mathrm{p}<0.05$ and $* * \mathrm{p}<0.01$

Figure 1. Structural mediation model

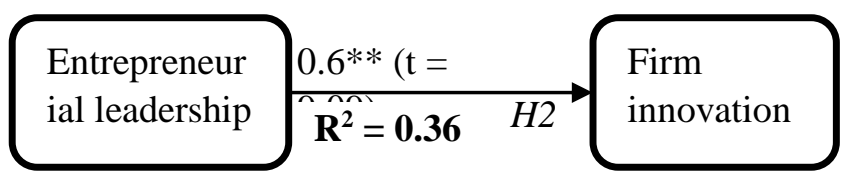

Note: Significant at: ${ }^{*} p<0.05$

Figure 2. Direct structural model

\section{CONCLUSIONS}

In this study, we show that entrepreneurial leadership and innovative work behavior are antecedents of firm innovation. Our results also indicate that an entrepreneurial leadership style may be necessary for the success of innovative performance. Several reasons for innovation become important and maybe a key to creating a competitive advantage for fashion products. First, fashion products are influenced by fashion trends, seasonal, weather conditions, advertising, and 
marketing. Therefore, the products need to adjust consumer demand, needs, and lifestyles when producing in large or limited quantities. Second, product life cycles are short and easily imitated by competitors. So they need to predict demand to avoid idle products because they are out of fashion or not following the trend anymore. However, fashion products will get loyal consumers and are willing to pay more, when they feel there is added value or feel their social status goes up when wearing clothes with certain brands. For those reasons, organizations need to facilitate and develop ideas and creativity to generate better entrepreneurial results. They should also identify the barriers that impede employees to be creative and even refuse to do anything new and attempt to eliminate them. Moreover, managers should improve employee's intrinsic and extrinsic motivate, such as give rewards in the form of incentives for employees who have succeeded in creating useful and profitable innovations, cultivating an atmosphere of fairness, transparency, and kinship.

\section{ACKNOWLEDGMENT}

This research work is supported by the Indonesia Endowment Fund for Education (LPDP).

\section{REFERENCES}

[1] H. Chaniago, "the Effects of Entrepreneurial Personality To Competitiveness and Corporate Image: a Study on Chocolate Agent Entrepreneurs," Int. Rev. Manag. Mark., vol. 10, no. 2, pp. 21-29, 2020 .

[2] L. Torkkeli, K. Puumalainen, and S. Saarenketo, Entrepreneurship in the Global Firm Article information:, vol. 6. Emerald Group Publishing Ltd, 2015.

[3] E. Akis, "Innovation and Competitive Power," Procedia - Soc. Behav. Sci., vol. 195, pp. 13111320, 2015.

[4] K. Kivipõld, “Organizational leadership capability - a mechanism of knowledge coordination for inducing innovative behaviour: A case study in Estonian service industries," Balt. J. Manag., vol. 10, no. 4, pp. 478-496, 2015.

[5] T. M. Amabile, "Componential Theory of Creativity," 2012.

[6] S. A. Woods, M. J. Mustafa, N. Anderson, and B. Sayer, "Innovative work behavior and personality traits: Examining the moderating effects of organizational tenure," J. Manag. Psychol., vol. 33, no. 1, pp. 29-42, 2018.

[7] N. Anderson, K. Potočnik, and J. Zhou, "Innovation and Creativity in Organizations: A
State-of-the-Science Review, Prospective Commentary, and Guiding Framework," J. Manage., vol. 40, no. 5, pp. 1297-1333, 2014.

[8] R. Wolniak and M. Grebski, "Innovativeness and creativity as factors in workforce development perspective of psychology," Sci. Pap. Silesian Univ. Technol. Organ. Manag. Ser., vol. 2018, no. 116, pp. 203-214, 2018.

[9] M. M. Hammond, N. L. Neff, J. L. Farr, A. R. Schwall, and X. Zhao, "Predictors of IndividualLevel Innovation at Work: A Meta-Analysis," Psychol. Aesthetics, Creat. Arts, vol. 5, no. 1, pp. 90-105, 2011.

[10] J. L. Farr, H. P. Sin, and P. E. Tesluk, "Knowledge Management Processes and Work Group Innovation," in The International Handbook on Innovation, no. 1, 2003, pp. 574-586.

[11] J. I. Jenssen and K. Aasheim, "Organizational Innovation Promoters and Performance Effects in Small, Knowledge-Intensive Firms,” Int. J. Entrep. Innov., vol. 11, no. 1, pp. 19-27, 2010.

[12] J. Rank, N. E. Nelson, T. D. Allen, and X. Xu, "Leadership predictors of innovation and task performance: Subordinates' self-esteem and selfpresentation as moderators," J. Occup. Organ. Psychol., vol. 82, no. 3, pp. 465-489, 2009.

[13] H. Zacher and K. Rosing, “Ambidextrous leadership and team innovation,” Leadersh. Organ. Dev. J., vol. 36, no. 1, pp. 54-68, 2015.

[14] D. J. Hughes, A. Lee, A. W. Tian, A. Newman, and A. Legood, "Leadership, creativity, and innovation: A critical review and practical recommendations," Leadersh. Q., vol. 29, no. 5, pp. 549-569, 2018.

[15] J. C. Ryan and S. A. A. Tipu, "Leadership effects on innovation propensity: A two-factor full range leadership model,” J. Bus. Res., vol. 66, no. 10, pp. 2116-2129, 2013.

[16] T. Anning-Dorson, "Innovation and competitive advantage creation: The role of organisational leadership in service firms from emerging markets," Int. Mark. Rev., vol. 35, no. 4, pp. 580 600, 2018.

[17] B. A. G. Bossink, "Leadership for sustainable innovation.: Torrens University Australia," Int. J. Technol. Manag. Sustain. Dev., vol. 6, no. 2, pp. 135-149, 2007.

[18] L. Gumusluoglu and A. Ilsev, "Transformational leadership, creativity, and organizational innovation," J. Bus. Res., vol. 62, no. 4, pp. 461473, 2009. 
[19] G. Yasin, S. Nawab, K. K. Bhatti, and T. Nazir, "Relationship of intellectual stimulation, innovations and smes performance: Transformational leadership a source of competitive advantage in smes," Middle - East J. Sci. Res., vol. 19, no. 1, pp. 74-81, 2014.

[20] F. C. Tung and T. W. Yu, "Does innovation leadership enhance creativity in high-tech industries?,” Leadersh. Organ. Dev. J., vol. 37, no. 5, pp. 579-592, 2016.

[21] R. D. Ireland, M. A. Hitt, and D. G. Sirmon, "A model of strategic enterpreneurship: The construct and its dimensions," J. Manage., vol. 29, no. 6, pp. 963-989, 2003.

[22] T. M. Amabile, "Motivational synergy: Toward new conceptualizations of intrinsic and extrinsic motivation in the workplace," Hum. Resour. Manag. Rev., vol. 3, no. 3, pp. 185-201, 1993.

[23] G. R. Oldham and A. Cummings, "Employee creativity: Personal and contextual factors at work," Acad. Manag. J., vol. 39, no. 3, pp. 607634, 1996.

[24] G. Surie and A. Ashley, "Integrating pragmatism and ethics in entrepreneurial leadership for sustainable value creation," J. Bus. Ethics, vol. 81, no. 1, pp. 235-246, 2008.

[25] A. Fontana and S. Musa, "The impact of entrepreneurial leadership on innovation management and its measurement validation," Int. J. Innov. Sci., vol. 9, no. 1, pp. 2-19, 2017.

[26] R. F. Hébert and A. N. Link, "The entrepreneur as innovator,” J. Technol. Transf., vol. 31, no. 5, pp. 589-597, 2006.

[27] P. M. Swiercz and S. R. Lydon, "Entrepreneurial leadership in high-tech firms: a field study," Leadersh. Organ. Dev. J., vol. 23, no. 7, pp. 380389, 2002.

[28] S. Huang, D. Ding, and Z. Chen, "Entrepreneurial leadership and performance in chinese new ventures: A moderated mediation model of exploratory innovation, exploitative innovation and environmental dynamism," Creat. Innov. Manag., vol. 23, no. 4, pp. 453-471, 2014.

[29] A. Bagheri, "The impact of entrepreneurial leadership on innovation work behavior and opportunity recognition in high-technology SMEs," J. High Technol. Manag. Res., vol. 28, no. 2, pp. 159-166, 2017.
[30] C. M. Leitch and T. Volery, "Entrepreneurial leadership: Insights and directions," Int. Small Bus. J. Res. Entrep., vol. 35, no. 2, pp. 147-156, 2017.

[31] F. A. A. Sawaean and K. A. M. Ali, "The impact of entrepreneurial leadership and learning orientation on organizational performance of SMEs: The mediating role of innovation capacity," Manag. Sci. Lett., vol. 10, no. 2, pp. 369-380, 2020.

[32] F. Patterson, M. Kerrin, G. G. Roissard, and P. Coan, "Everyday innovation: How to enhance innovative working in employees and organisations," United Kingdom, 2009.

[33] O. J. Odetunde, "Employee Innovation Process: An Integrative Model," J. Innov. Manag., vol. 7, no. 3, pp. 15-40, 2019.

[34] A. Newman, H. H. M. Tse, G. Schwarz, and I. Nielsen, "The effects of employees' creative selfefficacy on innovative behavior: The role of entrepreneurial leadership," J. Bus. Res., vol. 89, no. September 2016, pp. 1-9, 2018.

[35] F. Hakimian, H. Farid, M. N. Ismail, and P. K. Nair, "Importance of Commitment in Encouraging Employees' Innovative Behavior Introduction," Asia-Pacific J. Bus. Adm., vol. 8, no. 1, 2016.

[36] L. C. Chang and C. H. Liu, "Employee empowerment, innovative behavior and job productivity of public health nurses: a crosssectional questionnaire survey.," Int. J. Nurs. Stud., vol. 45, no. 10, pp. 1442-1448, 2008.

[37] K. Fitriani and N. Christi, "An Analysis of the Management of Supply Chain Risk: A Study of the Islamic Fashion Industry in Bandung, Indonesia," J. Bus. Econ. Rev., vol. 3, no. 1, pp. 11-17, 2018.

[38] Bekraf and BPS, Data Statistik dan Hasil Survei Ekonomi Kreatif, no. 2018.

[39] F. G. Ünay and C. Zehir, "Innovation intelligence and entrepreneurship in the fashion industry," Procedia - Soc. Behav. Sci., vol. 41, pp. 315-321, 2012.

[40] M. Renko, A. El Tarabishy, A. L. Carsrud, and M. Brännback, "Understanding and measuring entrepreneurial leadership style," J. Small Bus. Manag., vol. 53, no. 1, pp. 54-74, 2015.

[41] J. de Jong and D. den Hartog, "Measuring innovative work behaviour," Creat. Innov. Manag., vol. 19, no. 1, pp. 23-36, 2010.

[42] S. Scott and R. A. Bruce, "Determinants of Innovative Behavior: A Path Model of Individual Innovation in The Workplace," Acad. Manag. J., vol. 37, no. 3, pp. 580-607, 1994. 
[43] O. Janssen, "Job demands, perceptions of effortreward fairness and innovative work behaviour," J. Occup. Organ. Psychol., vol., no. 73, pp. 287-302, 2000.

[44] D. Gebert, S. Boerner, and R. Lanwehr, "The risks of autonomy: Empirical evidence for the necessity of a balance management in promoting organizational innovativeness," Creat. Innov. Manag., vol. 12, no. 1, pp. 41-49, 2003.

[45] D. I. Prajogo and A. S. Sohal, "The relationship between TQM practices, quality performance, and innovation performance: An empirical examination,” Int. J. Qual. Reliab. Manag., vol. 20, no. 8, pp. 901-918, 2003.

[46] W. F. Velicer, "identifiability problems," Educ. Psychol. Meas., vol. 36, pp. 149-159, 1976.

[47] J. C. Nunnally and I. H. Bernstein, Psychometric Theory, Third Edit. New York, USA: McGrawHil,1 Inc., 1994.
[48] P. . Bentler, "Comparative Fit Indexes in Structural Models," Psychol. Bull., vol. 107, no. 2, pp. 238246, 1990.

[49] L. R. Tucker and C. Lewis, "A Reliability Coefficient for Maximum Likehood Factor Analysis," Psychometrika, vol. 38, no. 1, pp. 421422, 1973.

[50] J. H. Steiger, "A note on multiple sample extensions of the RMSEA fit index," Struct. Equ. Model., vol. 5, no. 4, pp. 411-419, 1998.

[51] R. P. Bagozzi and Y. Yi, "On the evaluation of structural equation models," J. Acad. Mark. Sci., vol. 16, no. 1, pp. 74-94, 1988.

[52] J. M. R. Jimenez and M. del M. F. Fuentes, "Knowledge combination , innovation , organizational performance in technology firms," Ind. Manag. Data Syst., vol. 113, no. 4, pp. 523540, 2013. 